are much easier to deliver than universal vaccine programmes run separately for different infections.

One barrier to combined universal immunisation in infancy would be the unfounded anxiety some people feel about giving multiple antigens to babies. Furthermore, immune responses and clinical protection against Haemophilus influenzae type $\mathrm{b}$ is reduced in some combination vaccines, and British authorities want to ensure that any combined vaccine would not jeopardise control of other infections. ${ }^{9}$ A two dose (rather than three dose) schedule of hepatitis B vaccine could be given in adolescence instead. This schedule has been shown to be acceptable and effective in a deprived area of Glasgow and in the United States. ${ }^{11} 11$

Would universal vaccination against hepatitis B in the United Kingdom be too costly? This topic was discussed recently at a meeting of the Viral Hepatitis Prevention Board in Edinburgh. ${ }^{12}$ Health economics evaluations in countries with low endemicity have produced variable results, but most were done before vaccine prices were influenced by global markets. Vaccine costs, together with the burden of infection, are the most influential national measures in such economic evaluations. ${ }^{13}$ But the full economic burden of hepatitis B still needs to be established, including the direct costs of providing current and anticipated antiviral treatments for infection and of managing chronic liver disease and hepatocellular carcinoma, as well as the economic and personal costs of early deaths among carriers. If direct costs can be reduced by negotiated tendering, there can no longer be a financial argument against adopting a universal immunisation strategy against hepatitis B in the United Kingdom.

Jangu Banatvala emeritus professor of clinical virology (jangu@btopenworld.com)

King's College London School of Medicine, St Thomas's Campus, London SE1 7EH

\section{Pierre Van Damme director}

WHO Collaborating Centre for Control and Prevention of Viral Hepatitis, University of Antwerp, Belgium

Nedret Emiroglu adviser

Vaccine Preventable Diseases and Immunization, WHO Regional Office for Europe, Copenhagen, Denmark

Competing interests: PVD has been principal investigator of vaccine trials for several vaccine manufacturers, for which the University of Antwerp receives research grants.

1 WHO Expanded Programme on Immunisation, Global Advisory Group. Whly Epidemiol Rec 1992;3:11-6.

Beeching NJ. Hepatitis B infections: universal immunisation should be preferred in Britain. BMJ 2004:329:1059-60.

3 Hahné S, Ramsay M, Balogun K, Edmunds WJ, Mortimer P. Incidence and routes of transmission of hepatitis B virus in England and Wales, 1995-2000: implications for immunisation policy. J Clinical Virol 2004;29:211-20.

4 Department of Health. Getting ahead of the curve. A strategy for combating infectious diseases (including other aspects of health protection). London: $\mathrm{DoH}$ 2002

5 Van Damme P, Van Herck K. Leuridan E. Vorsters A. Introducing universal hepatitis B vaccination in Europe: differences still remain between countries. 2004. www.eurosurveillance.org/ew/2004/041118.asp (accessed 2 Mar 2006).

6 Chrystie I, Sumner D, Palmer S, Kenney A, Banatvala J. Screening of pregnant women for evidence of current hepatitis B infection: selective or universal? Health Trends 1992;24:1.

7 Aweis D, Brabin BJ, Beeching NJ, Bunn JEG, Cooper C, Gardner K, et al. Hepatitis B prevalence and risk factors for HBsAg carriage amongst Somali households in Liverpool. Commun Dis Public Health 2001;4:240-5.

8 Banatvala JE, Van Damme P. Hepatitis B vaccine-do we need boosters? J Viral Hepatitis 2003;10:1-6.

9 McVernon J, Andres N, Slack MP, Ramsay ME. Risk of vaccine failure after haemophilus influenzae type b (Hib) combination vaccines with acellular pertussis. Lancet 2003:361:1521-3.

10 Wallace LA, Bramley JC, Ahmed S, Duff R, Hutchinson SJ, Carman WF, et al. Determinants of universal adolescent hepatitis B vaccine uptake. Arch Dis Child 2004;89:1041-2.

11 Cassidy WM, Watson B, Ioli VA, Williams K, Bird S, West DJ. A randomized trial of alternative two and three dose hepatitis $\mathrm{B}$ vaccination regimens in adolescent: antibody responses, safety and immunologic memory. Paediatrics 2001:4:626-31.

12 Viral Hepatitis Prevention Board. Can the United Kingdom control viral hepatitis. VHPB meeting, Edinburgh, Nov 2005. www.vhpb.org (accessed 31 Jan 2006).

13 Beutels P. Economic evaluations of hepatitis B immunizations: a global review of recent studies (1994-2000). Health Econ 2001;10:751-74. doi 10.1136/bmj.38797.621516.47

\title{
The neglect of trauma surgery
}

\section{To improve outcomes, general trauma surgeons need training and recognition}

$\mathrm{M}$ any otherwise capable surgeons are challenged by seriously injured patients. Surgeons responding to the London bombings of 7 July 2005 had to contend with many cases of blast trauma and associated injury, but only a handful had experience of similar casualties. The management of severely injured patients is demanding because trauma does not respect the boundaries of anatomy or the surgical specialty. ${ }^{1}$ Yet the UK lacks both training opportunities for trauma surgery and a service infrastructure, problems that other countries have recognised and started to remedy.

The presence of a general surgeon in the multidisciplinary trauma team remains important: death from occult cavity haemorrhage is ranked second only to major head injury as a cause of death after resuscitative thoracotomy, damage control laparotomy, and rapid control of vascular injury are life saving, yet general surgeons working in the UK have few opportunities to develop expertise. ${ }^{3}$ More importantly, no formal training pathway exists for those wishing to achieve competence in trauma. In an era when higher surgical specialist training is subject to stringent accreditation this lack of provision is a conspicuous paradox.

Following the introduction of advanced trauma life support training and the trauma team approach, outcomes have improved, but progress has not been sustained. ${ }^{4}$ Efforts to improve training have been retarded by the absence of a dedicated trauma service infrastructure within the NHS. Demands from surgical institutions for a national framework for trauma management and centralisation of expertise have not been 
heeded. Instead, attempts to reorganise emergency care in England have concentrated on improving the "patient journey" and waiting times.

Delivery of trauma care is threatened by the inexorable rise of superspecialist training in elective disciplines and an ever diminishing pool of surgeons able to operate beyond their narrowed fields of expertise. Training has suffered after the implementation of the European Working Time Directive and may deteriorate further under the proposals for early postgraduate training, with their compressed training timelines. $^{5}$

New modes of non-operative injury management, pioneered in North America, have reduced surgical exposure to critical levels, and many US trauma surgeons supplement their duties by providing care for general surgical emergency cases. ${ }^{6}$ Despite this decline, North American traumatologists continue to enjoy dedicated training programmes and recognition of their discipline. In Britain, trauma has never been recognised as a separate surgical specialty beyond orthopaedic management of musculoskeletal injury. As younger specialties such as emergency medicine, interventional radiology, and critical care establish ever-expanding fields of responsibility, the general surgeon's role as a provider of holistic trauma care risks being fatally eroded.

Surgical trainees seeking training after their advanced trauma life support course have limited options. The definitive surgical trauma care course, run at a number of overseas centres, was developed by the International Association for Trauma and Surgical Intensive Care. The UK version, the definitive surgical trauma skills course, was initially designed to prepare military surgeons for operational deployment but has since found favour among motivated civilian surgeons. Core life saving surgical skills are taught over three days, using a mixture of expert panel discussions, case scenarios, and cadaveric workshops.

European and American surgeons have access to animals for training, but this option is not readily available in the UK, despite a provision for surgical training in the Animals (Scientific Procedures) Act 1986. Emerging technologies such as real time immersive virtual reality simulation ${ }^{7}$ offer promise but currently apply only to laparoscopic training, where haptic feedback is easier to generate. Ultimately, there is no substitute for supervised experience in high volume trauma centres such as those in North America or South Africa. However, given the absence of a suitable career structure, few individuals who obtain overseas trauma fellowships can exploit their skills on return to the UK.

Drawing on the findings on trauma of the forthcoming National Confidential Enquiry on Patient Outcome and Death, the UK's surgical institutions should fundamentally re-examine the issue of trauma training for surgeons. ${ }^{8}$ The royal colleges must ensure that the new intercollegiate surgical curriculum, currently being piloted, does not concentrate on superspecialist education at the expense of trauma and emergency surgical care. In particular, Britain needs a robust way of identifying, training, and accrediting a cadre of surgeons with the potential to become clinical champions of trauma services. Such a model has been adopted by the Royal Australasian Surgical College, which has formalised training paths in response to concerns that health services were losing future trauma leaders and service chiefs. ${ }^{9}$ Concerns among British military surgeons have led to innovative training packages designed to preserve corporate trauma expertise: these include obligatory overseas trauma fellowships and refresher attachments, a rolling programme of practical classes in all aspects of traumatology, and diploma certification..$^{10}$ Similarly, the needs of isolated communities in Scotland have driven the introduction of a training scheme in remote and rural surgery, which includes trauma skills training through attachments. $^{11}$

These programmes provide practical examples of how to provide focused trauma training, but any improvement risks being squandered unless accompanied by advances in service delivery. The recent establishment of the discipline of acute care medicine, with proposals for well defined, cross specialty registrar training, lead physicians, regional specialty advisers, and a national director, ${ }^{12}$ is attracting attention as a model for emergency surgical care. ${ }^{13}$ Sanctioning the birth of acute care surgery as a discrete discipline could provide a training path and career structure for trauma surgeons. More importantly, such a development may encourage a retooling of provision in a health service that has so far escaped all efforts to systemise the care of the seriously injured.

Nigel R M Tai specialist registrar in vascular surgery

Royal Free Hospital, London

James M Ryan

(james.ryan@ucl.ac.uk)

Leonard Cheshire professor of emergency medicine

University College Hospital, London

Adam J Brooks consultant surgeon

Queen's Medical Centre, Nottingham

Competing interests: JR is a convener of the definitive surgical trauma skills course, which is administered by the Royal College of Surgeons of England; AB and NT are faculty members. None receives any financial incentive through their association with the course.

1 Chaloner E. Blast injury in enclosed spaces. BMJ 2005;331:119-20.

2 Gilroy D. Deaths from blunt trauma after arrival at hospital: plus ça change, plus c'est la même chose. Injury 2005;36:47-50.

3 Brooks A, Butcher W, Walsh M, Lambert A, Browne J, Ryan J. The experience and training of British general surgeons in trauma surgery for the abdomen, thorax and major vessels. Ann R Coll Surg Engl 2002;84: 409-13.

4 Lecky FE, Woodford M, Bouamra O, Yates DW. Trauma Audit and Research Network. Lack of change in trauma care in England and Wales since 1994. Emerg Med J 2002;19:520-3.

5 Association of Surgeons of Great Britain and Ireland. Modernising medical careers and general surgery - a consensus statement. London: Association of Surgeons of Great Britain and Ireland, 2004.

6 Fakhry SM, Watts DD, Michetti C, Hunt JP. The resident experience on trauma: declining surgical opportunities and career incentives? Analysis of data from a large multi-institutional study.J Trauma. 2003;54:1-8.

7 Moorthy K, Vincent C, Darzi A. Simulation based training. BMJ 2005; 330:493-4.

8 www.ncepod.org.uk/studies.htm. Accessed 17 July 2005.

9 Roval Australasian College of Surgeons Trauma Committee. Report on training and career structures in trauma surgery. RACS, 1999.

10 Roberts P. Military surgery: initiatives and imperatives for training. London: Royal College of Defence Medicine, 2002.

11 Sedgwick D. Remote area surgery. Edinburgh: Royal College of Physicians of Edinburgh, 2005.

12 Royal College of Physicians. Acute care medicine: making it work for patients. A blueprint for organisation and training. London: RCP, 2004.

13 Giddings AEB, Cripps J. Developing a modern surgical workforce. London: Giddings AEB, Cripps J. Developing a modern
Royal College of Surgeons of England, 2005. 